\title{
Why the econometrician is in good spirits: a workshop through the looking glass
}

\author{
Carl Hampus Lyttkens
}

Received: 28 November 2008/ Accepted: 8 January 2009/Published online: 12 February 2009

(C) Springer-Verlag 2009

\begin{abstract}
Vita brevis, ars longa (or...life is too short for abstracts).
\end{abstract}

Keywords Health · Econometrics · 1066 .

Hitchhiker's guide

JEL Classification $\quad \mathrm{C} 01 \cdot \mathrm{I} 12 \cdot \mathrm{Z} 19$

\section{Introduction (a note on footnotes: they increase the explanatory power of the text)}

This paper aims to explore the determinants of researchrelated quality of life (RRQoL) of econometricians in health economics. It is well known (standard expression for not bothering to look up the references) that an extensive literature deals with the measurement and determinants of health-related quality of life (HRQoL) of the general population. However, if the standard neo-classical paradigm applies (self-interested, utility maximising behaviour, etc.), scientists are of course much more interested in the wellbeing of scientists than of other people.

In addition to its intrinsic interest, this is an important issue for public policy. Analogous to the extra-welfarist approach in health economics [8], where it is argued that maximisation of health (not welfare) is a reasonable objective for the allocation of a health care budget, we may

C. H. Lyttkens $(\bowtie)$

Department of Economics, Lund University,

P.O. Box 7082, 22007 Lund, Sweden

e-mail: carl_hampus.lyttkens@nek.lu.se assume that the purpose of allocating funds to the scientific community is to maximise their RRQoL. We may also safely assume that this interpretation is endorsed by the scientists in question (supplier-induced demand).

While these issues are of considerable general interest, the analysis here focusses on individuals engaged in econometrics and health economics, due to the availability of a unique data set from the 16th European workshop on Econometrics and Health Economics (cf. "Data and method").

The analysis is based on a scientific principle established by Sellar and Yeatman [10]), who showed that "history is what you can remember." 1 This led them to such eloquent deductions as the observation (p 83) that, after the Glorious Revolution, England was ruled by an orange (Williamanmary) or that the Danish conquest of England was a Good Thing as it was the cause of Alfred the Cake (p 16). ${ }^{2}$ Similarly, economics can be defined as those economic analyses that are memorable. Hence it comprises such important findings as the deadweight loss of Christmas $[13]^{3}$ or that males can maximise their survival probability

\footnotetext{
${ }^{1}$ So far this principle is based on what people actually remember when asked about their recollection of, e.g., the Battle of Hastings, which, as everybody knows, represents one of the (two) memorable dates in English history [10]. Hopefully, this unsophisticated approach will soon be replaced by rigorous economic analyses, which will allow us to model what individuals would remember if they were rational.

2 Nevertheless, some bias is discernible even in this brilliant scholarship, as it is claimed that the beginning of political economy was a Bad Thing (p 47).

3 Though this particular result may soon cease to be memorable as, e.g. in the United States, it is no longer pc to use religiously biased terminology.
} 
by becoming $185 \mathrm{~cm}$ tall or more [4]. ${ }^{4}$ Following the Sellar-Yeatman principle, the analysis below is based on the author's recollection of the workshop in question. The power of the recollection test is enhanced by the fact that the author is not an econometrician (but the probability that the author misunderstood anything or everything said and done at the workshop has not been subjected to a likelihood ratio test). To minimise recollection bias, the first draft of the paper was composed during the very early morning flight (06.55 a.m.) from Bergen to Copenhagen (survival analysis).

\section{Previous literature}

Happily none. ${ }^{5}$

\section{Theoretical framework 6}

\section{Data and method}

No economics students were available so standard experimental methods could not be used. Instead, data was collected at an ambulatory laboratory, the European Workshop on Econometrics and Health Economics, which in 2007 moved to Bergen, Norway. As this brings together some 40-50 highly qualified subjects (health econometricians) for observation each year, it represents a unique data source that until now has not been used to investigate anything, which provides ample motivation for the present

\footnotetext{
${ }^{4}$ This assumes that the ruler in society does not take too literally the advice of Thrasybulos (tyrant of Miletos), who, when asked by an envoy from his friend and colleague Periander (tyrant of Corinth) about how he should rule as a tyrant, took the envoy on a walk through a cornfield, where he did not utter a word of counsel, but cut off all the tallest stalks (as told by Herodotos [6]). Cf. also the remark attributed to the manager of the national handball team from the Soviet Union: "it is easier to teach tall guys to play handball than to teach short guys to grow taller."

5 There are, however, some approaches that are similar in spirit, if not in subject matter, such as the analyses of religion as a DUP activity [3]

${ }^{6}$ The text in this section was deleted in anticipation of the helpful suggestions of the potential referees of the paper (backwards induction), in order to eliminate theory bias (who needs it?) and selection bias (who would read it?). The merits of this decision have to be judged on the basis of a more general framework, entailing, e.g. the benefits of ex-post construction of hypotheses, constant relative theory aversion, theory as a DUPL (directly unproductive plodding) activity, and the hazard function for obfuscating trivia by algebra (which usually has a statistically significant time trend). If theoretical arguments appear in the following text, they should be treated as random shocks (or possibly fixed effects).
}

study. ${ }^{7}$ The respondents were followed for a period of 3 days (panel data).

The sample consists of those who applied and were accepted to the workshop and managed to get to Bergen (double hurdle model with sample selection). The same individuals can be drawn for several workshops (bootstrapping), but we use only the latest wave, treating the previous waves as pilot studies. The sample includes both male and female econometricians (unobservable heterogeneity).

One might reasonably ask how RRQoL is related to utility, which would be the standard maximand in an economic approach. It is well known (again) that the relationship between HRQoL and utility is tenuous. It feels safe to maintain, however, that RRQoL is an important element in the utility function of the economist. In fact, anecdotal information and eyeball regressions using observations at conferences, workshops, seminars, lunch rooms (in short, everywhere scientists meet) suggest that RRQoL is paramount in the utility function, to the possible exclusion of all other arguments. The author therefore argued with himself whether perhaps RRQoL is best represented by a lexicographic preference relation (defined over success in research and a composite good) rather than a standard utility function. This, however, is a theoretical question, and therefore we choose instead to investigate which model best described the data (cf. "Theoretical framework"). After trying $X \in[1, \infty)$ functional forms, we finally managed to show that a standard utility function applied.

Utility is defined over current life and posterity. Scientific status after time $\mathrm{T}^{\text {healthmin }}$ (when the individual decides to die in the deterministic version of the Grossman model [5]) will enter the individual's utility either if he is somehow around to experience it (as envisaged by Twain [11]), so that RRQoL is maximised over $\left(\mathrm{T}=0, \ldots, \mathrm{T}^{\text {healthmin }}, \ldots\right.$, $\mathrm{T}^{\mathrm{JD}}$; where $\mathrm{JD}=$ judgement day) or if an increase in RRQoL in posterity has an independent effect on current utility.

We assume that RRQoL is a positive function of appreciative comments ${ }^{8}$ from the floor and getting published (with lags and weights). We also include health among the potential determinants, as it appears unwise to ignore health issues in the present context (strategic publication bias). We faced an endogeneity problem, in that the remarks from the floor may be affected by the presenter's RRQoL (also known as the flattery effect). Hence

\footnotetext{
7 The author of this paper was also present at the workshop, so in essence we are dealing with participant observation, but since that is a qualitative approach (in sociology to boot) it clearly does not qualify as scientific. Instead we are treating the author's contributions as censored observations.

${ }^{8}$ Dummy variables are used to control for helpful comments (where, e.g. "you need better data" does not count).
} 
peer appreciation was instrumented by the share of participants that did not fall asleep (if post-lunch session) or turned up (morning session), which we just identified as relevant instruments.

The respondents were subjected to several treatments (in the parlance of experimental economics), in order to investigate the determinants of their RRQoL. If respondents were unable to answer the questionnaire (gone asleep, upstairs, etc.), proxy respondents were used (a convenience sample drawn from the authors of this paper). We investigated RRQoL by asking the respondents to answer the following question: "scientifically speakingdo you feel good". Hence in the analysis below, RRQoL is treated as a latent variable and we used a probit model. ${ }^{9}$

To anchor the RRQoL estimates, a film (directed by Francis Ford Copula) of the gala dinner at the Nobel prize celebrations was shown to the participants, who rated it on a visual analogue scale (with "beastly boring" $=0$, and "better than Bond/Bardot" = 1). ${ }^{10}$ Next, they took part in a time trade-off exercise, to determine their RRQoL of being present at the dinner as a Nobel laureate. Reports from focus groups have confirmed that there will be no hypothetical bias in the answers, as this is something the respondents had thought of repeatedly (cf. the fact that everybody reports that their individual probability of traffic accidents is below average).

To investigate the determinants of RRQoL, respondents were asked what they felt about the choice of referees for their papers (standard gamble), the length of the publication process (time trade-off), and to eventually having their papers published (random utility theory).

Dummy variables were used to distinguish (1) participants who never turned up at the workshop after having read about the average rainfall in Bergen, ${ }^{11}$ and (2) participants who had also been present at the workshop where eel in many different varieties was the only item on the menu at the conference dinner (leading to attrition in the panel). ${ }^{12}$ In order to investigate health effects, we studied the effects of food dispersion (overloading one's plate at the smorgasbord or going several times) on obesity, and we

\footnotetext{
${ }^{9}$ In the pilots, we tried a format with several levels of RRQoL (ordered probit), but then the answers all regressed towards the mean RRQoL.

${ }^{10}$ Note the gender-sensitive formulation. This is rarely found among male economists (Wilcoxon-Mann-Whitney).

11 2,100 mm yearly, in case you did not know, of which $283 \mathrm{~mm}$ in September, the month of the workshop. Consequently we had decided against any attempt to take account of the effects of bad weather on RRQoL, as we expected no variation in that explanatory variable at this workshop. Retrospectively, this was a mistake, as it did not rain all the time (a good thing).

12 As a jolly good start to becoming memorable, yours truly was the local organiser of that workshop.
}

tried to control for the distribution of nut allergies in the study population (Kernel density).

As a final exercise, the participants were taken up on a mountain (or "hill" if it had not taken place in Norway or Wales) to look at the "utsikt" (untranslatable word in the Bergen dialect-the German "Aussicht" and French "belle vue" come close, but in plain English the best approximation is "fog").

After each treatment, the respondents placed the data in envelop(e)s for analysis, and we began by testing whether the results were affected by how many frontiers the respondent had passed on the way to Bergen. Our analysis showed, however, that this just produced a lot of white noise (in the Nordic countries often referred to as "snow" [7]). Separate regressions were run on the quantile of respondents expected to arrive last at the workshop (those who came after dinner). This could be important because the analysis of the data-envelop(e)s is sensitive to outliers who miss their flights (random shocks) and the stochastic frontier analysis assumes that we know the process that relates border-crossing to late arrival (note: the answer is not always SAS).

\section{Results}

As a preliminary exercise, we tried to model the respondents' decision to enter the discipline of health economics (sample selection), but there was no variation in the sample, as everybody answered, "what the heck, man, it's a living," showing conclusively that this decision is determined exogenously by concerns over life and death.

The results from the TTO Nobel prize exercise showed that being a laureate carried the weight 5.0 (where total bliss $\equiv 1.0$ ), providing at long last a balance to the worsethan-death category in HRQoL studies. The use of proxy respondents showed a severe underestimation of the unmet demand for peer appreciation. We speculated that the choice of econometric method in the papers could have an indirect effect on RRQoL, and therefore tried to model these choices (multinomial logit) but failed (rejection of the IIA property).

Since we asked the respondents to self-assess their RRQoL (also known as mining the data), an important finding was that the respondents did in fact have private information ${ }^{13}$ about the quality of their work (according to the "know thyself" principle, discovered by the Oracle in Delphi already before Arrow [2] ${ }^{14}$ ).

\footnotetext{
${ }^{13}$ Some of the inspirations for this and what follows in this section can be deduced by checking out the list of papers presented at the workshop [9].

${ }^{14}$ Compulsory reference in health economics.
} 
With respect to health, factor analysis showed that the participants were all nicely loaded when a factor such as BMI (beer median intake) was high. This suggests a link with the memorable result that some alcohol intake is better for your salary than being a teetotaller or engaging in heavy drinking (overview in van Ours [12]). As the workshop was preceded by a master's course, it would have been interesting to investigate the effects on fertility of this education effect (natural experiment), but it is not known if any respondent changed pregnancy status during the workshop (unobservable heterogeneity).

An attempt by the investigator to model individual heterogeneity in preferences using a discrete choice experiment failed because there were too few attributes in the choice set, and all economists know that utility is a nondecreasing function of the alternatives in life. Therefore the respondents lexicographically chose to add an alternative, and exited the laboratory at this point. A major concern is always if participants are telling you the truth (biases aplenty), but fortunately this could also be solved by IV-technique (in vino veritas) in the evening sessions. Furthermore, after the respondents had all logged out, we concluded that they were all quite normal.

The main result, however, was that-as expected-the RRQoL of the participants was uniformly and unequivocally equal to 42 [1].

\section{Concluding remarks}

It is important to continue this line of research, and therefore we explored the participants' interest, should it take place in Monte Carlo, in participating in the next workshop. However, the respondents only simulated an interest in this question, being preoccupied with the present (hyperbolic discounting). While it can be shown that this investigation has contributed significantly to the QoL of the author, it remains to be seen if this is true for the readers as well. ${ }^{15}$

With a human capital approach, future analyses ought to consider how the reputational stock evolves over time and the nature of depreciation. Is there a natural tendency for the rate of depreciation to increase with age, as in the Grossman model, so that the researcher decides to scientifically die (not to be confused with die scientifically) at some specific point in time? This could be typical of Western society and its high-status sciences. In the humanities, building on the heritage from antiquity, "recently published" may well mean 10 years ago; in economics it would hardly indicate more than 3 years ago (and in medicine it suggests within 6 months).

Future research should also investigate the sensitivity of our results to religious affiliation [choice of god (including goods as god, also called the no-good no-god option), gender of god, single or multi-attribute god, merciful or avenging god, god aversion, etc.]. Obviously attitudes towards, e.g. re-incarnation would affect the influence of different factors on RRQoL, depending on how the marginal effect of living in human memory affects the marginal utility you have as - say - a bat? It remains to be seen if battiness is a complement or a substitute to RRQoL.

Conflict of interest The author wishes to acknowledge that he hopes to participate in future workshops.

\section{References}

1. Adams, D.: The hitchhiker's guide to the galaxy. Pocket books, New York (1979). ISBN 0-671-46149-4

2. Arrow, K.: Uncertainty and the welfare economics of medical care. Am. Econ. Rev. 53, 941-973 (1963)

3. Bhagwati, J.N., Srinivasan, T.N.: Religion as DUP activity. Public Choice 48, 49-54 (1986). doi:10.1007/BF00239559

4. Fogel, R.: Economic growth, population theory, and physiology: the bearing of long-term processes on the making of economic policy. Am. Econ. Rev. 84, 369-395 (1994)

5. Grossman, M.: On the concept of health capital and the demand for health. J. Polit. Econ. 80, 223-255 (1972). doi:10.1086/259880

6. Herodotus.: Books V-VII. Loeb Classical Library, Harvard University Press, Boston (1982)

7. Hoeg, P.: Miss Smilla's feeling for snow. Vintage, New York (1996)

8. Hurley, J.: An overview of the normative economics of the health sector. In: Culyer, A.C., Newhouse, J.P. (eds.) Handbook of health economics, vol. 1A. North-Holland, Amsterdam (2000), pp 55-118

9. Jones, A.M., O’Donnell, O. (eds.): Introduction. Health Econ. 17, 997-998 (2008). doi:10.1002/hec.1384

10. Sellar and Yeatman: 1066 and all that. Methuen, London [1975 (1930)]

11. Twain, M.: Extract from Captain Stormfield's visit to heaven. Harper, New York (1909)

12. van Ours, J.C.: A pint a day raises a man's pay; but smoking blows that gain away. J. Health Econ. 23, 863-886 (2004). doi: 10.1016/j.jhealeco.2003.12.005

13. Waldfogel, J.: The deadweight loss of Christmas. Am. Econ. Rev. 83, 1328-1336 (1993)

\footnotetext{
$\overline{15}$ If there is an underlying message in this paper, it is probably (Kolmogorov-Smirnov one sample test) that while there is too little theory in empirical work, there is also too little realism in economic theory.
} 